\title{
The Atmospheric Ozone in Relation to Upper Meteorological Conditions
}

\author{
by \\ K. Kawamura \\ Meteorological Research Institute \\ (Received December 24, 1956)
}

\begin{abstract}
The relations between the amount of atmospheric ozone observed at Tokyo for the period from 1953 to 1955 and the upper meteorological conditions were studied.

Day-to-day variations of the ozone amount are generally explained with the conception of upper pressure pattern, that is a high ozone amount near a trough and a low amount near a ridge. But, in addition to this the vertical motions of the upper atmospheric air accompanied by a jet stream may be considered as a secondary effect. Moreover, in the southern-most region of the trough at $300 \mathrm{mb}$ level, ozone variations were essentially small. The result shows that in this region the intensity of the vertical motions of the air contributing to ozone variation is less than in the other regions of the trough.
\end{abstract}

\section{Introduction}

Recently, LANGLO [1] investigated the latitudinal variation of the mean annual amount of the atmospheric ozone using the data hitherto obtained at various places of the world. From this result, he pointed out that a relatively rapid fall in the ozone amount takes place somewhere between $45^{\circ}$ and $25^{\circ} \mathrm{N}$., depending on the longitude. This interpretation can be easily accepted because this zone roughly divides the atmosphere into the polar air having a high ozone content and the tropical air having a low ozone content. According to this point of view, it is more reasonable to consider that the above-mentioned fall in the ozone amount may take place in the region of atmospheric jet streams [2]. If this is accepted, the essentially high ozone amount at Zi-Ka-Wei near Shanghai as noticed by CRAIG [3] and LANGLo [1] can be, in some degree, explained, because the central core of maximum wind in the upper atmosphere in the Far East is located more to the south than that of Western Europe. Moreover, this jet stream accompanies vertical motions of the air around the central core [4], and by this motion the total ozone amount observed at a ground station can possibly be affected in its amount to some degree.

However, day-to-day variations of the ozone amount are already explained by Normand [5], Miyake and Kawamura [6] considering the upper pressure pattern. 
The role of these two factors in the variation of ozone amount observed at Tokyo is statistically studied here.

\section{Description of materials}

\section{a). Ozone}

The data of atmospheric ozone amount used here are obtained at Meteorological Research Institute $\left(35^{\circ} 42^{\prime} \mathrm{N}\right.$., $139^{\circ} 39^{\prime} \mathrm{E}$.), Tokyo using the apparatus consisting of a cadmium photoelectric tube sensitive to the light of wave length shorter than about $3,250 \mathrm{~A}$ and a suitable glass filter. The observations were made at about 11 a.m. $(0200 \mathrm{Z})$ on days when there was no cloud in the direction of the sun and 217 independent observations were obtained during the period from June 1953 to September 1955. Fortunately, during the above period the same observation with Dobson spectrophotometer (No. 52) was carried out at Aerological Observatory, Tateno $\left(36^{\circ} 03^{\prime} \mathrm{N}\right.$., $140^{\circ} 08^{\prime} \mathrm{E}$. $)$. Comparing observations with the present apparatus and the Dobson spectrophotometer, the absolute values of ozone amount observed by the former apparatus could be determined by that of the latter. With this observation, it was ascertained that the present apparatus can determine the ozone amount with fair accuracy. The detailed description of the result

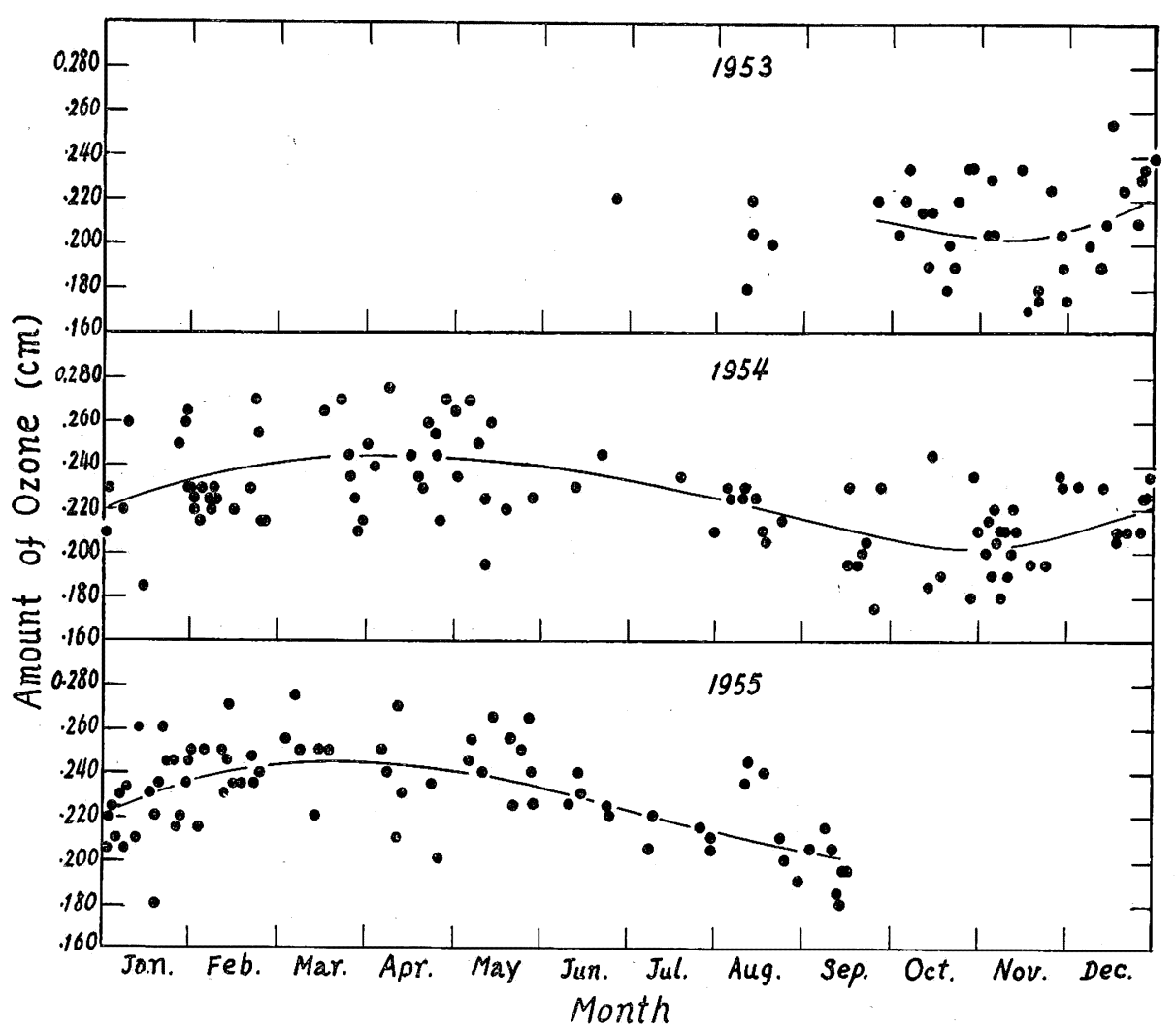

Fig. 1. Seasonal variation in the amount of atmospheric ozone observed at Tokyo $(1953 \sim 1955)$. 
of this comparative observation is already reported in our previous paper [7] and the results of ozone observation for the above-mentioned period are shown in Fig. 1. The curves representing the seasonal variation of the ozone amount for respective years were determined by smoothing the mean values of the respective calendar months with a curve.

\section{b). Meteorological data}

Meridional cross-sections along $140^{\circ} \mathrm{E}(0300 \mathrm{Z}$ ) were used as necessary meteorological data, in which the positions of atmospheric jet streams are given since September 1954. These were constructed by the Forecaster Section, Japan Meteorological Agency, Tokyo. 500 and $300 \mathrm{mb}$ synoptic charts (0300Z) published by the Japan Meteorological Agency were also used.

On examining the meridional cross-sections, it was found that the atmosphere generally consisted of a single jet stream on days when ozone observations were carried out. This was the case even if it was a period usually having double jet streams, that is April-July and September-October, as shown by First Weather Wing [8]. This apparently strange phenomenon perhaps may be due to the fact that northern latitudes above about $45^{\circ} \mathrm{N}$ were not taken into account in the construction of daily meridional cross-section, because of lack of data. When there are double jets, the meridional position of the northern jet is generally located further north than that of Tokyo. From this reasoning, it can be said that the southern jet was taken into consideration for the case of double jets.

According to the literature cited above, the central core of maximum wind over Japan $\left(140^{\circ} \mathrm{E}\right)$ reaches its southern-most position $\left(33^{\circ} \mathrm{N}\right)$ in February and the northern-most $\left(42^{\circ} \mathrm{N}\right)$ in August.

\section{Results}

From the analysis of wind data in the upper atmosphere, it is known that the jet stream axis on individual days fluctuate over wide ranges of latitude. Because the jet is located at a height of about $200 \mathrm{mb}$ at which the ozone content is to some degree great; 'the vertical motions of the air accompanied by this will affect the ozone amount. Fortunately, the daily axes are moved over Tokyo either to the north or to the south during most of the year. Therefore, it is convenient to study the relations between the day-to-day variations of the ozone amount and that of the latitudinal position of the jet.

As shown in the previous section, day-to-day ozone variations are experimentally explained considering the upper pressure pattern, that is to say, a high ozone amount near a trough and a low amount near a ridge. We have tried statistically to find the additional effect on ozone variation with the vertical motions of air in the vicinity of a jet. In connection with these, the distribution of ozone deviations near troughs or ridges are examined. An illustration of these ozone variations is shown in Fig. 2. In the figure, the ozone amount $\left(10^{-3} \mathrm{~cm}\right)$ observed for the period from May 19 through 28, 1955, are related to $300 \mathrm{mb}$ synoptic charts and the jet streams. The figures in round brackets indicate the ozone amount obtained by the zenith sky light observation using Dobson spectrophotometer at Aerological Observatory, Tateno. The positions of jet streams 
19. $5.55(0300 z)$

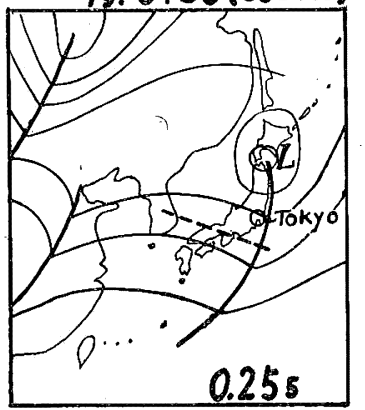

23.5 .

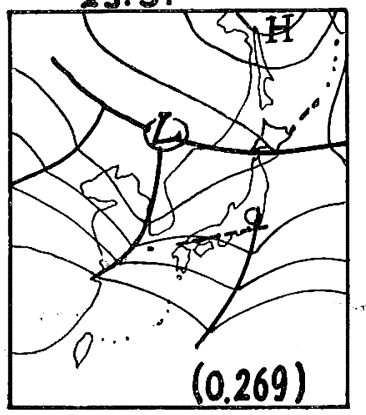

26.5 .

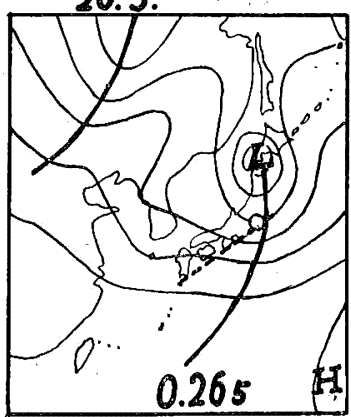

20. 5 .

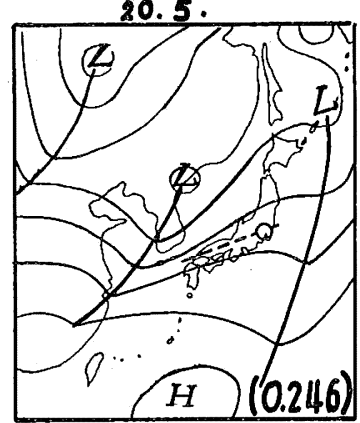

24.5

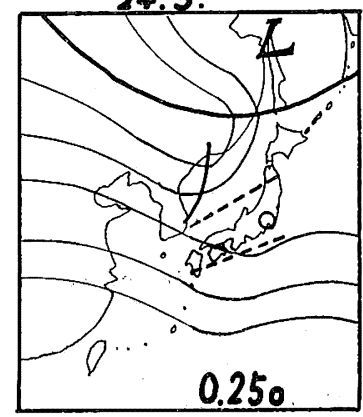

27.5 .

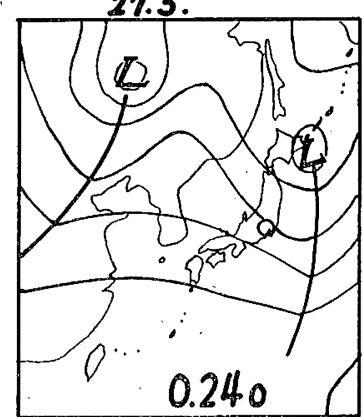

21.5

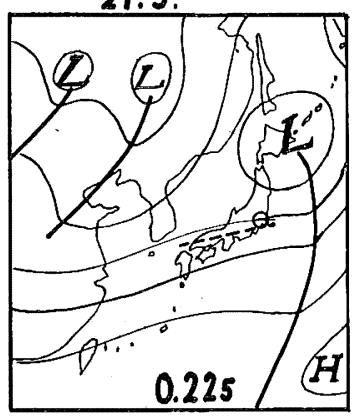

25.5.

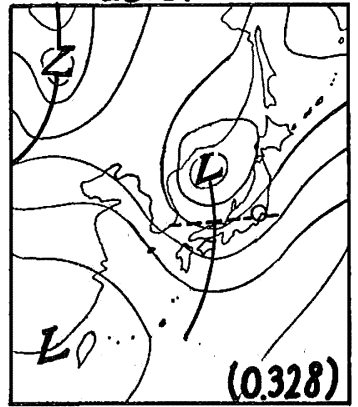

28.5.

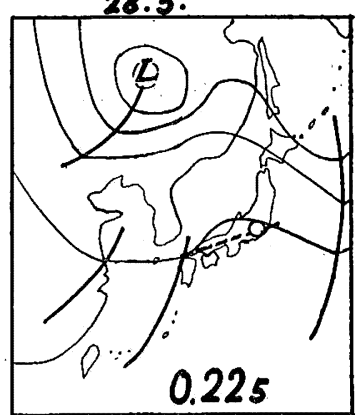

Fig. 2. $300 \mathrm{mb}$ synoptic charts on the days when the ozone observation has been carried out at Tokyo and Tateno. Latitudinal positions of the jet streams are shown by broken lines. The ozone amount are also given by figures in each chart.

shown by broken line were determined by assuming that the central cores of maximum wind depicted in both cross-sections along $130^{\circ}$ and $140^{\circ} \mathrm{E}$ are continuous. On May 20, 21 and 28, the contour lines over Tokyo show anticyclonic curvature and the ozone amount observed there is essentially low. On the contrary, the region of trough has a high ozone amount. These relationships are applicable to most of the other cases, independent of the season of year. However, in the intermediate zone between a trough and a ridge, there have at times been observed higher ozone amounts than near the trough. More detailed analysis showed that the observing station was located to the north of a jet stream in 
cases of ozone increment in the rear of a trough. This irregularity of ozone variation may be connected with the vertical motion of the air in the vicinity of the jet stream, which was deduced from the theory of jet formation by Namias and Clapp [4]. From Fig. 2, we cannot find any relations between the ozone amount and the latitudinal position of the jet stream. This presumably resulted from the observed fact that ozone variations are dependent primarily on the upper pressure pattern.

Fig. 3 shows the relations between the ozone $\left(10^{-3} \mathrm{~cm}\right)$ in terms of the deviation from the curves of the mean seasonal variation (Fig. 1) and the latitudinal

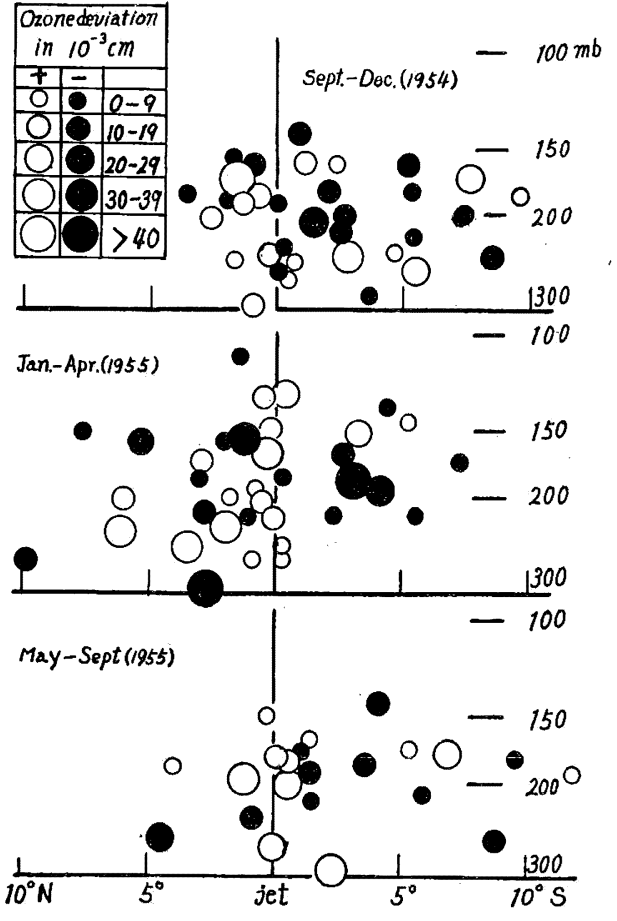

Fig. 3. Ozone deviations at Tokyo relative to the latitudinal position of an atmospheric jet stream.

Ordinates show the height of jet stream in millibars and abscissae the latitudinal distance in degrees between the center of the jet stream and the observing station, the former being taken as the origin. position of the jet stream. Because the jet fluctuates with season over wide ranges of latitude, these relations are shown by. separating into three periods, that is September-December, 1954, January-April and May-September, 1955. In the figure, ordinates show the height of the jet stream in millibars and abscissae the latitudinal distance in degrees between the center of the jet stream and the observing station, the former being taken as origin. The distributions of the ozone deviation in each period show that the north side of the jet center (left side in the figure) is not always occupied with the positive deviation and that the same feature holds even when examined differentially with respect to each height of the jet. It is, however, interesting to note that the large ozone deviations are found within several latitude degrees south or north of the jet center through each season of year. This observed fact also shows that the ozone amount may be affected by the vertical motions in the vicinity of a jet center.

In general, the jet stream blows across the trough lines at high levels as shown in Fig. 2. The region of the trough near this point of intersection at $300 \mathrm{mb}$ level may have a large ozone deviation because of the intense vertical motion of the air. In this case, the role of the jet stream on ozone variation may not be distinguished from the pressure effect. For this reason, we have tried to see the distribution of ozone deviations near troughs or ridges at 500 and $300 \mathrm{mb}$ levels using the ozone data obtained since 1953. A schematic result at $300 \mathrm{mb}$ level is shown in Fig. 4. Because of scanty data for the region near the low pressure center, detailed description of ozone variations is omitted from the figure. The 
ozone-pressure pattern relationship as mentioned above can, however, be considered to apply even in this region. The figure shows that a high ozone amount is generally observed near the trough line, a low ozone amount near the ridge line, and an intermediate ozone amount in the southernmost region of the trough and in the regions between the trough and the ridge, respectively. These relations can be seen more clearly at $300 \mathrm{mb}$ level than at $500 \mathrm{mb}$. The small ozone

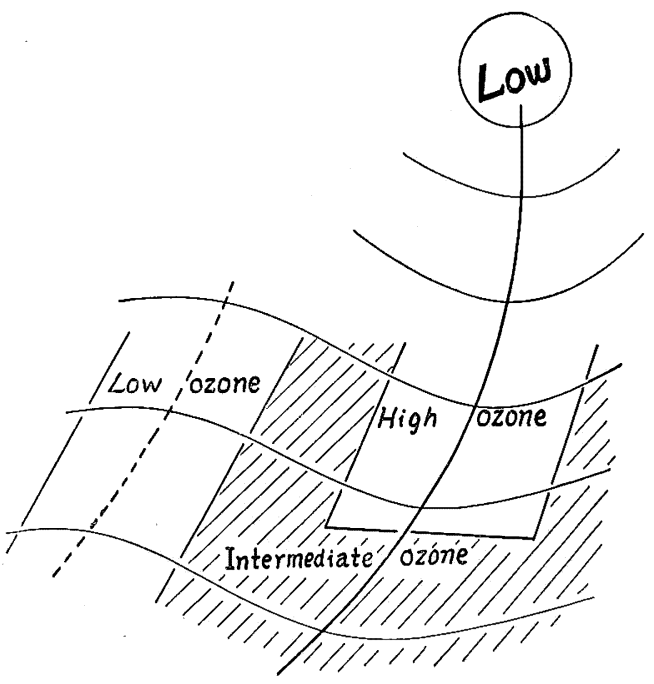

Fig. 4. Schematic diagram of the distribution of ozone amount in relation to a pressure pattern at $300 \mathrm{mb}$ level. variations near the southernmost region are presumably connected with the characteristic of low latitude ozone as shown by KarandiKar [9]. Moreover, these can probably be attributed to the comparatively smaller vertical motions of the air in this region.

Thus we have found that we cannot clearly distinguish the role of the jet stream in the ozone variation from the ozone-pressure pattern relationship so long as we accept that the vertical motion is most active near the intersecting region between a jet stream and a trough.

\section{Conclusion}

Day-to-day variations of the upper pressure pattern are the main cause of ozone variation. However, it is asserted here that the vertical motions of the air in the vicinity of a jet center may possibly affect the total ozone amount. In connection with this, we have noticed that in the southernmost region of a trough at $300 \mathrm{mb}$ level, smaller ozone deviations are observed.

It is difficult to determine with a single observation whether the north side of the jet center has essentially a higher ozone amount than that of the south side. To prove this, network observations along a longitude are necessary for a fairly long period. When this effect is proved to exist, the longitudinal variation of the mean annual amount of ozone must be taken into consideration, because the axis of the jet stream meanders around the hemisphere.

In the present paper, the treatment of the relations between the ozone and the position of the northern jet are omitted because the jet is generally located too far north from the observing station. It may be supposed that the above effects appear more clearly in the case of northern jet.

Acknowledgements - The author wishes to express his hearty thanks to Dr. Y. MiYake, Chief of the Geochemical Laboratoay, Meteorological Research Institute, for his encouragements and valuable advice and to $\mathrm{Mr}$. M. YAMASAKI and his co-workers, Aerological Observatory, for their kind help during the comparative observation. 


\section{References}

[1] Langlo, K., 1952 ; On the Amount of Atmospheric Ozone and Its Relation to Meteorological Conditions. Geofys. Publ., 18, No. 6.

[2] Ramamathan, K.R., 1954: Physical Research Laboratory, Ahmedabed, Nature, 174, No. 4441. p. 1078.

[3] CraIG, R.A., 1950: The Observations and Photochemistry of Atmospheric Ozone and Their Meteorological Significance. Meteor. Monogr., 1, No. 2.

[4] Namias, J., and P.F. C..APP, 1949: Confluence Theory of the High Tropospheric Jet Stream. J. Meteor., 6, p. 330.

[5] Normand, C., 1953: Atmospheric Ozone and the Upper-air Conditions. Quart. J. Roy. Meteor. Soc., 76, p. 39.

[6] Mixake, Y., and K. Kawamora, 1954: Studies on the Atmospheric Ozone at Tokyo. Pap. Met. Geophys., 5, p. 178.

[7] Kawamura, K., 1956: Results of the Observation of Atmospheric Ozone at Tokyo (in Japanese). Journ. Met. Soc. Japan, 34, p. 231.

[8] First Weather Wing, 1956: Far East Climatology of the Jet Stream (Special Study No. 105-1). Tokyo, F.W.W. p. 112.

[9] Karandikar, R.V., 1948: Studies in Atmospheric Ozone-Part II, Proc. Indian Acad. Sci., 28, p. 63. 